\title{
UNA HISTORIA DEL PRIMER PROGRAMA LATINOAMERICANO DE POSTGRADO EN EDUCACIÓN MATEMÁTICA
}

\section{Uma história do primeiro programa latino americano de pos-graduação em educação matemática}

\section{$A$ bistory of the first latin american postgraduate program in mathematical education}

\author{
Vanesa Pacheco Moros \\ Universidad de Carabobo (Valencia, Venezuela) \\ Correo-e: vanepache74@gmail.com
}

Fredy Enrique GonzÁLEZ

Universidad Federal do Rio Grande do Norte (Brasil)

Correo-e: fredygonzalezdem@gmail.com

Dedicatoria

Este trabajo está dedicado al profesor Mauricio Orellana Chacín, primer venezolano graduado como matemático en la Facultad de Ciencias de la Universidad Central de Venezuela, fundador de los Estudios de Postgrado en Educación Matemática en América Latina.

Resumen: El estudio que aquí se reporta ofrece una versión de la historia del programa de Maestría en Educación Matemática del Instituto Pedagógico de Caracas, Venezuela (MEM-IPC), fundado en 1974 y actualmente vigente. Se detallan los pormenores de la creación de dicho programa con el propósito de ofrecer argumentos que muestren que este fue el primero de los programas de postgrado en Educación Matemática creados en América Latina.

Palabras clave: Historia; Educación Matemática; campo científico; Mauricio Orellana. 
Resumo: O estudo aqui relatado oferece uma versão da história do programa de Mestrado em Educação Matemática do Instituto Pedagógico de Caracas, Venezuela (MEM-IPC), fundado em 1974 e atualmente em vigor. Alguns detalhes da criação desse programa são descritos a fim de oferecer argumentos que mostram que este foi o primeiro dos programas de pós-graduação em Educação Matemática criados na América Latina.

Palavras-chave: História; Educação Matemática; campo científico; Mauricio Orellana.

ABSTRACT: The study reported here offers a version on the history of the Master's program in Mathematics Education of the Pedagogical Institute of Caracas, Venezuela (MEM-IPC), founded in 1974 and currently in force. Some of the details of the creation of said program are described in order to offer arguments that show that this was the first of the postgraduate programs in Mathematics Education created in Latin America.

KEY WORDS: History; Mathematics education; Scientific Field; Mauricio Orellana.

\section{Introducción}

E l Instituto Pedagógico Nacional (actualmente conocido como Instituto Pedagógico de Caracas, IPC) fue creado en 1936 y constituye la primera institución de educación superior venezolana dedicada a la formación de profesores. Su fundador e ideólogo fue Mariano Picón Salas (I90i-1965), quien en 1923 se residenció en Chile, y se graduó como historiador en la Universidad de Santiago de Chile en 1928, en la cual, además de fesor de las asignaturas Historia del Arte y Literatura, regentó el cargo de rector en 1932 (Agudelo, 20I6).

Cuando Picón Salas regresó a Venezuela en 1936, se incorporó al Ministerio de Educación, y junto con un grupo de profesores provenientes de la Universidad de Santiago de Chile adelantó acciones para la creación de una institución que pudiera satisfacer la necesidad, que en aquel momento tenía el país, de formar docentes para la enseñanza de las diferentes asignaturas contempladas en los planes de estudio de la educación preuniversitaria. Esa institución fue el Instituto Pedagógico Nacional (IPN), el cual fue creado en Caracas como Escuela Normal Superior mediante decreto firmado por el presidente, general Eleazar López Contreras, el 30 de septiembre de 1936.

En el art I. ${ }^{\circ}$ de su decreto fundacional, al IPN se le asignó la misión de «formar el profesorado para la enseñanza secundaria y normalista; cooperar al perfeccionamiento del profesorado en servicio; fomentar el estudio científico de los problemas educacionales y de la orientación vocacional; y realizar investigaciones 
UNA HISTORIA DEL PRIMER PROGRAMA LATINOAMERICANO DE POSTGRADO EN EDUCACIÓN MATEMÁTICA

VANESA PACHECO MOROS Y FREDY ENRIQUE GONZÁLEZ

pedagógicas sobre educación, especialmente sobre educación venezolana» (Agudelo, 2016: I6).

Desde su fundación hasta 1958, el IPN se mantuvo como la única institución venezolana de educación superior dedicada a la formación de docentes para la educación preuniversitaria. Con el advenimiento de la democracia, a raíz del derrocamiento del dictador Marcos Pérez Jiménez, en el país fueron fundadas otras instituciones similares. Así, el 6 de noviembre de 1959, fue fundado el Instituto Pedagógico de Barquisimeto en el estado Lara. Posteriormente, fueron creados institutos pedagógicos en los estados Aragua, Maturín y Miranda.

En 1983, con motivo del Bicentenario del Libertador Simón Bolívar, los institutos pedagógicos de Barquisimeto, Caracas, Maracay, Maturín y Miranda, junto con el Instituto Pedagógico Rural «El Mácaro», el Instituto Pedagógico Rural «Gervasio Rubio» y el Instituto de Mejoramiento Profesional del Magisterio, que hasta entonces funcionaban de forma autónoma, fueron integrados para conformar la Universidad Pedagógica Experimental Libertador (UPEL), creada mediante Decreto n. ${ }^{\circ} 2176$ de fecha 28 de julio de 1983.

La estructura original del Instituto Pedagógico de Caracas debió ser modificada para adaptarse a su condición de núcleo de la UPEL. En la actualidad el IPC cuenta con una diversidad de especialidades (Arte, Biología y Química, Matemática y Física, Castellano y Literatura y Latín, Ciencias de la Tierra, Educación Especial, Educación Física, Geografía e Historia, Idiomas Modernos; además de Prácticas Docentes, Pedagogía y Tecnología Educativa) que satisfacen tanto las exigencias de formación inicial de los profesores de Educación Secundaria en Venezuela como las de formación posgraduada; para esto último son ofrecidas diversas opciones en especializaciones, maestrías y doctorados. Es en relación con este contexto que se realizó el estudio que en este artículo se reporta, referido a los pormenores de la creación del programa de Maestría en Educación Matemática con el propósito de ofrecer argumentos que muestren que este fue el primero de los programas de postgrado en Educación Matemática creados en América Latina.

\section{Maestría en Enseñanza de la Matemática (MEM) del Instituto Pedagógico de Caracas}

El fundador de la Maestría en Enseñanza de la Matemática del IPC es el profesor Mauricio José Orellana Chacín. A continuación, expondremos una breve semblanza suya. El profesor Orellana nació en Caracas (Venezuela) el 30 de abril de 1940. En 1962 se graduó de Licenciado en Matemática en la Facultad de Ciencias de la Universidad Central de Venezuela, convirtiéndose así en el primer matemático puro de Venezuela.

Realizó estudios de doctorado en el Instituto de Pesquisas Matemáticas de la Universidade de São Paulo en Brasil (1966-1967). Al culminarlos viajó a Francia 
donde estudió en la Universidad de Grenoble, una vez obtenido en 1968 el $D i$ plôme d'études approfondies (DEA) en Mathématiques Pures, continuó sus estudios doctorales en la Faculte des Sciences de esta misma Universidad, los cuales culmina obteniendo el Doctorat de Troisieme cycle de Mathématiques Pures, en 1970. Ha sido profesor en la Universidad Central de Venezuela, en la Universidad Centro Occidental «Lisandro Alvarado» y la UPEL, en Venezuela, así como en varias instituciones de educación superior extranjeras, entre las que destacan el Instituto Tecnológico de Estudios Superiores de Monterrey (México) y el Instituto de Pesquisas Matemáticas de São Paulo (Brasil).

Orellana Chacín fue miembro del Comité Interamericano de Educación Matemática (1973-1975) y presidente del Comité Organizador Local de la IV Conferencia Interamericana de Educación Matemática (IV CIAEM), realizada en Caracas (diciembre de 1975). Ha presentado múltiples trabajos y conferencias en diversas instituciones de Educación Secundaria, Formación Docente y Universidades, y en Seminarios y Congresos en Venezuela, Argentina, Brasil, México, Cuba, España, Francia, Bélgica y Estados Unidos. En 1983, realizó una estancia de seis semanas en la Universidad de Laval de Quebec con el profesor Claude Gaulin. Ha escrito numerosos artículos y otros trabajos diversos sobre Historia de la Matemática en Venezuela, y libros de texto -para Educación Secundaria y Superior- y de divulgación de la Matemática para todos los niveles educativos. Recibió la Orden José María Vargas en primera clase, Universidad Central de Venezuela, 1985. Profesor Titular (jubilado), Universidad Central de Venezuela, 1986. En la última década ha estado investigando sobre la interdisciplinariedad e importancia de las artes, arquitectura, pintura y vida cotidiana en la Enseñanza de la Matemática.

\section{I. Nacimiento de la Maestría en Enseñanza de la Matemática del IPC (MEM-IPC)}

Los pormenores acerca de la emergencia de la MEM-IPC fueron establecidos con base en una entrevista semiestructurada, realizada por la autora de este trabajo, al profesor Orellana Chacín en la residencia de este el día 2I de septiembre de 20I9. De viva voz, él expresó que, en I97I, el jefe del Departamento de Matemática y Física del IPC era el profesor José Alejandro Rodríguez, quien participó como delegado por Venezuela en la Tercera Conferencia Interamericana de Educación Matemática (III CIAEM) realizada en Bahía Blanca (Argentina) en 1972, uno de cuyos temas de discusión fue la Matemática Moderna.

Ese mismo año un grupo de profesoras especialistas en matemática, originarias de Francia y Estados Unidos, fue invitado a Venezuela, a dictar cursos sobre la Matemática Moderna y los cambios en la Enseñanza de la Matemática que estaban teniendo lugar a nivel mundial. Tales cursos pusieron en evidencia la necesidad de actualizar los conocimientos de los profesores venezolanos que enseñaban matemática en los niveles preuniversitarios. Las reflexiones compartidas 
VANESA PACHECO MOROS Y FREDY ENRIQUE GONZÁLEZ

entre los expertos invitados, los profesores participantes en sus cursos y los profesores del Departamento de Matemática y Física del IPC, involucrados en la actividad, convergieron en que era recomendable formalizar y sistematizar esos y otros cursos, para lo cual se consideró adecuada la creación de un programa de maestría en enseñanza de la Matemática.

En 1973, el profesor José Alejandro Rodríguez dejó vacante la Jefatura del Departamento de Matemática y Física del IPC, la cual fue asumida por el profesor Jesús Andonegui, quien había sido alumno del profesor Mauricio Orellana. Andonegui le propuso a Orellana que le acompañara al IPC para fundar un programa específico de Maestría en Educación Matemática. El profesor Orellana era personal de la Facultad de Ciencias de la Universidad Central de Venezuela (UCV); por ello, al aceptar la invitación, el profesor Orellana invirtió uno de sus años sabáticos más otro año de permiso remunerado para poder cumplir con las actividades correspondientes a tan importante compromiso académico. Una de las primeras responsabilidades que le fueron asignadas al profesor Orellana fue la de hacer ajustes en el Reglamento de Estudios de Postgrado del IPC a los fines de conferirle un marco legal e institucional adecuado al programa de maestría que habría de ser propuesto.

Una de las modificaciones importantes fue la caracterización de los estudios de postgrado; los cuales fueron organizados en tres categorías: actualización, ampliación y especialización. Los estudios de ampliación tenían como finalidad la extensión de conocimientos en determinada área; tendrían una carga horaria mayor a la de los cursos de actualización, y no conducían a la obtención de título académico, aunque quienes los culminaran exitosamente podrían obtener un certificado (diploma) de aprobación. Los estudios de especialización conducían al título de Magíster con la mención correspondiente. Teniendo en cuenta esta modificación reglamentaria, el profesor Orellana consignó ante la Jefatura del Departamento de Matemática el proyecto intitulado «Curso de actualización y nivelación para aspirantes a la Maestría en Enseñanza de la Matemática».

\subsection{El Proyecto de Maestría en Enseñanza de la Matemática (1973)}

El proyecto para desarrollar la Maestría en Enseñanza de la Matemática en el IPC fue elaborado por el profesor Mauricio Orellana con la colaboración de un equipo de profesores integrado, entre otros, por Marín Damianoff, Saulo Rada, Margarita Castro, Federico Martin, Trinidad de Barboza, Ricardo Tascón y Jesús Andonegui. Este último, en su condición de jefe de departamento, recibió el proyecto en octubre de 1973 .

Dado que, por vez primera, en Venezuela serían ofrecidos estudios postgraduados en enseñanza de la Matemática, resultó necesario clarificar su sentido puesto que, hasta ese momento, los programas de postgrado relacionados con Matemática que se desarrollaban en el país hacían énfasis en formar «matemáticos» con una orientación hacia la investigación, para desempeñarse en Educación 
Superior y dentro de una determinada rama de la Matemática ${ }^{1}$. De allí la importancia de caracterizar adecuadamente la Maestría, orientándola explícitamente hacia la enseñanza de la Matemática, lo cual quedó definido en sus objetivos. En el primero de estos quedó claro que la MEM-IPC tenía como intencionalidad fundamental mejorar la preparación del profesorado que enseñaba Matemáticas en Educación Media y Matemáticas Generales en el nivel básico de la Educación Superior.

Dicha preparación implicaba no solo capacitación para enseñar la Matemática que estaba prevista en los planes de estudio vigentes en ese momento, sino también capacidad para innovar y afrontar con éxito futuras modificaciones curriculares relacionadas con la Matemática a enseñar, derivadas de los avances que pudieran estar aconteciendo en el seno de la propia Matemática. Por ello, «el egresado de estos cursos deberá estar capacitado para proseguir estudios más avanzados y comenzar a realizar investigaciones dentro de la Educación Matemática» (Orellana, 1973: 3).

La duración de los estudios de la MEM-IPC fue establecida en tres periodos académicos (semestres) de 15 o I6 semanas cada uno. Los cursos eran de dos tipos: obligatorios y electivos. Inicialmente fueron considerados los siguientes: Álgebra; Análisis Real; Geometría; Estadística y Probabilidad; Historia de la Matemática; Técnicas de Investigación en Educación Matemática; Didáctica de la Matemática en la escuela media; Seminario I (orientado a completar la formación matemática con la participación activa del alumno en la preparación y exposición de un tema y en la discusión de los otros); Seminario II (orientado a discutir problemas de enseñanza de la Matemática y tópicos afines, en especial a nivel de Educación Secundaria, a fin de que sirviera de orientación para la praxis educativa), y trabajo especial de grado, consistente en una «investigación original o en el desarrollo total o parcial de un tema especializado fundamentado en trabajos originales de revistas, libros especializados y memorias u otros trabajos de grado. [...] debe orientarse hacia la Enseñanza de la Matemática y afines» (Orellana, 1973: 7).

Las modalidades para desarrollar las clases fueron las siguientes: (I) Teóricas, consistentes en exposiciones magistrales a cargo del profesor encargado de la gestión académica del curso; (2) Prácticas, consistentes en la resolución de ejercicios, propuestos con por lo menos una semana de anticipación a la clase, para demostrar no solo la comprensión de los contenidos, sino también la habilidad operatoria y nivel de razonamiento; (3) Dirigidas $u$ Orientadas: «modalidad propia de los seminarios, de la elaboración del trabajo especial de grado y de las asesorías para atender las dudas de los estudiantes en la realización de los ejercicios y prácticas de las asignaturas matemáticas» (Orellana, 1973: 5).

Entre los requisitos de ingreso era exigida la posesión de título de Profesor en la especialidad de Matemática, conferido por alguno de los institutos pedagógicos venezolanos, o un título equivalente conferido por alguna universidad venezo-

Orellana (I980, pp. I3I-I47) ofrece una panorámica amplia de la situación de los estudios de postgrado en el área de Matemática existentes en Venezuela para esa época. 
VANESA PACHECO MOROS Y FREDY ENRIQUE GONZÁLEZ

lana o extranjera. La aceptación de títulos obtenidos en estudios realizados en programas no venezolanos dependía de la satisfacción de algunos requisitos evaluativos adicionales, tales como su traducción oficial al español y su valoración por los tres miembros de una comisión especialmente designada para tal efecto. El número máximo de alumnos por sección era de 30 y en algunos cursos se podían aceptar oyentes.

Para evaluar el desempeño académico de los estudiantes de la MEM-IPC, en los cursos teóricos y prácticos, se aplicaban diversas estrategias: (I) Pruebas escritas de Resolución de Problemas; (2) Pruebas orales individuales sobre contenidos teóricos; (3) Informes escritos para reportar la solución de problemas previamente asignados; (4) Apreciación, por el profesor, de la actuación del estudiante basada en la realización de consultas, cumplimiento de las tareas asignadas y la realización de lecturas complementarias; (5) Exposiciones orales en el aula sobre soluciones dadas a problemas propuestos; (6) Reportes de trabajos en grupo; (7) Respuestas a un cuestionario final elaborado por el profesor.

La evaluación de los cursos Dirigidos u Orientados era diferente dado su carácter. Cada alumno debía realizar una exposición oral, un RESUMEN escrito y un examen final, escrito u oral, relativo al tema del Seminario que le hubiera sido asignado y a dos de los temas desarrollados por sus compañeros. Además, la aprobación exigía un mínimo del 80\% de asistencia a las actividades.

El trabajo especial de grado era evaluado por un jurado de tres miembros, entre quienes estaba el tutor del candidato. A cada jurado se le entregaba un ejemplar del trabajo con un mes de anticipación y, finalizado este plazo, se procedía a convocar al alumno a fin de que lo defendiera. Las opciones evaluativas eran: No Aprobado, Aprobado, Excelente.

La aprobación de todas las asignaturas concedía el derecho a un diploma; cuando el alumno aprobaba el Trabajo Especial de Grado, se le confería el título de «Magíster en Enseñanza de la Matemática».

\subsection{Los cursos de actualización y nivelación para aspirantes a la Maestría en Enseñanza de la Matemática}

Entre los aspirantes a ingresar en la MEM-IPC, se encontraban profesores que carecían de información sobre la Matemática enseñada a nivel superior y otros que deseaban prepararse mejor para incrementar sus posibilidades de cursarla exitosamente. Para atender a estos profesores se consideró pertinente ofrecerles cursos de actualización y nivelación cuyo contenido fundamentalmente se refería al manejo de conceptos básicos y no tanto a cuestiones de carácter operatorio. El apoyo a la ejercitación de los procedimientos operatorios implicados en la resolución de los problemas o en la realización de los ejercicios se realizaba de forma individualizada, con la mediación de profesores que atendían las consultas de los estudiantes. 
El contenido de estos cursos fue organizado en unidades: Unidad I (Teoría de Conjuntos, Propiedades básicas del Sistema de los Números Reales); Unidad 2 (Divisibilidad en los Números Enteros, Teorema Fundamental de la Aritmética, Congruencias); Unidad 3 (Teoría de Grupos, Anillos de Polinomios, Espacios Vectoriales); Unidad 4 (Conceptos fundamentales del Cálculo Diferencial en una variable; Cálculo Diferencial en varias variables; Cálculo integral en una, dos y tres variables, Integral de Riemann; Sucesiones y Series); Unidad 5 (Axiomas de la teoría de probabilidades. Probabilidad condicional).

La convocatoria a inscribirse en el primer curso se realizó mediante avisos de prensa; el primero fue publicado el 26 de enero de 1974 en el Diario El Punto y el segundo al día siguiente, 27 de enero de 1974, en el Diario El Nacional. Esta acción promocional tuvo gran impacto ya que se inscribieron 34 participantes.

\subsection{El primer Curso de Ampliación en Matemática asociado con la MEM-IPC}

El primer Curso de Ampliación en Matemática fue inaugurado el día 4 de febrero de 1974 y sus clases culminaron el 25 de mayo de ese mismo año. Los profesores Federico Martin, Saulo Rada y Mauricio Orellana fueron los responsables de dictar todos los contenidos de este primer curso, cuyos participantes eran profesores de Educación Secundaria, quienes asistían a las clases tres veces a la semana, en horario nocturno.

Quien expuso la Clase Magistral de Inauguración fue el profesor Federico Martin, desarrollando los contenidos correspondientes a la Unidad I (Conceptos fundamentales de la Teoría de Conjuntos). La segunda clase tuvo lugar el iz de febrero de 1974 y fue ofrecida por el profesor Saulo Rada, quien continuó con los contenidos correspondientes a la Unidad I. Luego, el curso fue asumido por el profesor Mauricio Orellana, quien, el i8 de febrero de 1974, disertó sobre los contenidos correspondientes a la Unidad 3 (Subgrupos, Teorema de Lagrange, Subgrupos normales, Grupo cociente, Homomorfismo de grupos y Teorema fundamental del homomorfismo).

Todos los participantes culminaron este primer curso. No obstante, un número importante de ellos no formalizó su inscripción en la MEM-IPC, debido a que las clases se ofrecían en horario nocturno y a muchos de los profesores que aspiraban ingresar les resultaba imposible asistir a clases durante ese horario.

El primer curso de ampliación estuvo orientado a fortalecer los conocimientos matemáticos de los participantes; de hecho, las prácticas consistían fundamentalmente en actividades de resolución de problemas relativos al contenido matemático que estuviese siendo tratado. Los cursos de ampliación tuvieron una duración de Ioo horas, y durante el periodo 1974-1975 fueron desarrollados tres (enero-mayo de 1974; junio-noviembre de 1974; marzo-julio de 1975). Quienes cumplían las cien horas de clase y aprobaban las evaluaciones correspondientes recibían un diploma que certificaba tal hecho 
UNA HISTORIA DEL PRIMER PROGRAMA LATINOAMERICANO

DE POSTGRADO EN EDUCACIÓN MATEMÁTICA

VANESA PACHECO MOROS Y FREDY ENRIQUE GONZÁLEZ

\subsection{Discusión y aprobación del Proyecto de la Primera MEM-IPC}

La diligencia y el compromiso de sus colaboradores le permitieron al profesor Orellana consignar ante la Jefatura del Departamento de Matemática el Proyecto de MEM-IPC en octubre de 1973 y la modificación del Reglamento de Postgrado en noviembre de ese mismo año. Con base en este Reglamento, fue ofrecido el primer curso de ampliación en febrero de 1974. Paralelamente al desarrollo de este curso, desde la Jefatura del Departamento de Matemática se continuaron los trámites administrativos correspondientes a los fines de lograr la definitiva aprobación institucional de la Maestría.

El 4 de abril de 1974, el subdirector académico del Instituto Pedagógico de Caracas, profesor Guillermo Cedeño, dirige una comunicación al jefe del Departamento de Matemática y Física, profesor Jesús Andonegui, indicándole que el proyecto de MEM-IPC sería sometido a estudio por los miembros de la Comisión Central de Currículo, la Oficina de Postgrado y el Servicio de Currículo, y que, una vez realizadas las observaciones a las que hubiese lugar, él, junto con el equipo que intervino en la elaboración del proyecto, serían convocados a una reunión con la Comisión Central para discutir dichas observaciones. Dicha reunión, en efecto, se llevó a cabo y en ella la Comisión Central solicitó una nueva versión del proyecto en el que se incluyeran las modificaciones derivadas de las observaciones realizadas.

\subsection{Proyecto Maestría en Enseñanza de la Matemática (versión definitiva)}

La versión definitiva del proyecto de MEM-IPC, atendiendo las modificaciones sugeridas por la Comisión Central de Currículum del IPC, fue consignada el I7 de mayo de 1974. Entre los argumentos ofrecidos para justificarla destacan los siguientes:

I. Articulación con los planes del Departamento de Matemática y Física del IPC en cuanto al ofrecimiento de oportunidades de actualización y especialización a sus egresados.

2.A diferencia de los otros programas de postgrado existentes para la época que estaban orientados hacia la investigación dentro de las diversas áreas de la Matemática, esta maestría tiene una orientación explícita hacia la enseñanza de la Matemática y está destinada a la formación de profesores que enseñan Matemática.

3. Las asignatura y programas fueron seleccionadas tomando en cuenta la realidad nacional relativa a la formación de los docentes; los cambios curriculares ocurridos en los diferentes niveles del sistema educativo nacional, y el potencial impacto educativo de los avances ocurridos dentro de la propia ciencia Matemática. 
En síntesis, esto afirmaban los proponentes del proyecto:

Estamos seguros que la Maestría en Enseñanza de la Matemática es una necesidad en el país: muchos colegas, con espíritu de superación, ven frustradas sus esperanzas al no ofrecerse facilidades para la salida al exterior en condición de becarios; además, nuestro país ha formado suficientes recursos humanos en Universidades extranjeras que le permiten desarrollar Maestrías como estas con éxito suficiente (Orellana, 1974: 2).

En consonancia con su orientación hacia la Educación Matemática, la MEMIPC se propuso como objetivos:

I. Profundizar la preparación del profesorado de matemática de Educación media y superior en el desarrollo actual de la enseñanza de esta Ciencia [...]; 2. Capacitar al profesorado a fin de que pueda hacer innovaciones, ser creativo dentro de su campo de acción [...]; 3 . Especializar al profesorado en el área de la Enseñanza de la Matemática [...]; 4. Capacitar al profesorado de manera que al egresar de estos cursos pueda proseguir estudios más avanzados [...] (Orellana, 1974: 3).

El plan de estudios debía completarse en cuatro periodos regulares de entre i4 y 16 semanas de duración y contemplaba cursos (obligatorios y electivos) porcentualmente divididos de la forma que se detalla a continuación:

I. Asignaturas de especialización (Álgebra, Análisis, Geometría, Probabilidad y Estadística, Historia de la Matemática, Didáctica de la Matemática en la Escuela Media, Seminario I, Seminario II), $80 \%$.

2. Asignaturas del área de educación (Técnicas de Investigación Educativa), $15 \%$.

3. Asignaturas electivas (Seminario Sobre Problemas de la Educación Media, Seminario Sobre Problemas de la Educación Superior, Dinámica de Grupos, Computación Educativa, Geometría no Euclidiana, Lógica Simbólica, Axiomática de la Teoría de Conjuntos, Nuevas Técnicas de Administración Aplicadas a la Educación), $5 \%$.

Para obtener el título de Magíster era imprescindible aprobar un mínimo de 30 unidades-crédito en una escala de I a 9 puntos, con mínima aprobatoria de 5 puntos (aunque al final el aspirante a Magíster debía obtener un promedio mínimo de 6 puntos), demostrar dominio instrumental de un idioma diferente al castellano y presentar una tesis de grado orientada hacia la Enseñanza de la Matemática. Para esta presentación era imprescindible haber aprobado por lo menos 20 unidadescrédito.

Los cambios más significativos en el proyecto presentado en octubre de 1973 estuvieron relacionados con el cumplimiento de requisitos establecidos en el Reglamento de Estudios de Postgrado del Instituto Pedagógico de Caracas: duración de los estudios, los cursos que deberían ser ofrecidos y el apoyo bibliográfico y documental. 
UNA HISTORIA DEL PRIMER PROGRAMA LATINOAMERICANO DE POSTGRADO EN EDUCACIÓN MATEMÁTICA

VANESA PACHECO MOROS Y FREDY ENRIQUE GONZÁLEZ

En lo que respecta a la duración de los estudios, en el Proyecto MEM 1973 (PMEM73) se programó una duración de 2 semestres académicos; en el Proyecto Versión Final MEM 1974 (PVFMEM74) se planteó que la duración de los estudios fuese de cuatro periodos regulares, es decir, 4 semestres.

En cuanto a los cursos, en el PMEM73 había un curso que se denominaba Análisis Real que pasó a denominarse Análisis (para contemplar espacios de dimensión superior a I), no había cursos electivos; en el PVFMEM74 se agregaron los siguientes seminarios electivos: Problemas de la Educación Media, Problemas de la Educación Superior, Dinámica de grupos, Computación Educativa, Geometría no Euclidiana, entre otros. Por último, se presentó un listado con publicaciones diversas relacionadas con la Investigación en Educación Matemática para el participante de la MEM.

El 17 de mayo de 1974 fue aprobado por el Consejo Académico Directivo del Instituto Pedagógico de Caracas el PVFMEM74; las inscripciones de los profesores que aspiraban ingresar a la MEM fueron realizadas durante la última semana del mes de agosto de 1974, y el 2 de septiembre de 1974 inició su accionar académico propiamente dicho.

Es importante mencionar que, aun después de haber sido aprobada en mayo de 1974 la versión final del Proyecto de Maestría en Enseñanza de la Matemática, los Cursos de Ampliación continuaron siendo ofrecidos. Así, el i4 de junio de 1974 fue publicada en la prensa la convocatoria a inscripciones para el $2 .{ }^{\circ}$ Curso de Ampliación en Matemática, a ser desarrollado entre los meses de junio y noviembre de ese año. Un aliciente para atraer participantes a este curso fue el ofrecimiento de que quienes lo culminaran satisfactoriamente, se podrían inscribir para conformar el segundo grupo de estudiantes de la MEM que iniciaría sus actividades académicas en febrero de 1975.

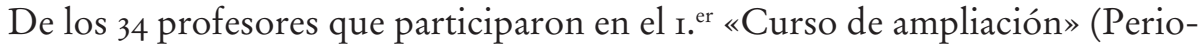
do enero 74-mayo 74), solo se inscribieron en el primer grupo de estudiantes de la MEM-IPC los siguientes profesores y profesoras: José Clemente Ventura, María Trinidad Rojas de Barboza, Germania Sánchez, Blanca Rojas, Nelson Tovar, Alfredo Trejo, Tania Calderín, Pedro José Colina Oraá, Alexis Rodríguez, Eduardo González, Miriam Solís, Filomena de Risi y Jorge Núñez.

Las primeras asignaturas que debieron cursar los integrantes del primer grupo de participantes de la MEM fueron Análisis, Álgebra e Historia de la Matemática, esta última administrada por el profesor Mauricio Orellana.

\subsection{Acciones académicas iniciales de la Maestría en Enseñanza de la Matemática}

Las asignaturas correspondientes al Plan de Estudios de la MEM comienzan a dictarse el 2 de septiembre de 1974. Su primer grupo de estudiantes estuvo conformado por los I3 profesores nombrados en la sección anterior, quienes habían participado en el primer curso de ampliación y, en su mayoría, trabajaban en Educación Secundaria. Las clases eran dictadas tres días a la semana en un horario 
comprendido entre las seis de la tarde y las ocho de la noche. Adicionalmente, para los seminarios se planificaban actividades a ser realizadas durante los sábados; por tanto, el régimen de estudio requería disponibilidad de tiempo suficiente para cumplir con las exigencias del programa.

Estos primeros participantes se inscribieron para cursar todas las asignaturas ofrecidas para el primer semestre. Ya a partir del segundo periodo hubo participantes que inscribian un solo curso por periodo, lo cual afectó negativamente su prosecución académica, al punto que hubo algunos que comenzaron en 1974 y culminaron en la década de los ochenta y otros en la década de los noventa. Otros factores, no atribuibles a los participantes, que pudieron haber incidido sobre el bajo número de egresados durante los primeros años del desarrollo de la MEM fueron algunas modificaciones introducidas en el Plan de Estudios, que alteraron en parte la filosofía subyacente en su concepción original.

En 1976, el profesor Orellana cesó en sus funciones como coordinador, y los nuevos directivos del programa introdujeron cambios significativos. El primero de ellos fue la eliminación de los cursos de ampliación, cuya última edición se desarrolló entre marzo y julio de 1975; sus profesores facilitadores fueron: Federico Martin, Saulo Rada, Julián Chang y Rafael Orellana, quien era especialista en Estadística y actuó como profesor invitado.

Los cambios fueron tan sustantivos que produjeron una reorientación del programa; lo cual convirtió a la MEM-IPC en una Maestría más «Matematizada»; esto afectó la idea inicial de que la MEM constituyese un programa dirigido tanto a los profesores de Educación Secundaria como a los profesores encargados específicamente de los primeros semestres de carreras universitarias, para que desarrollaran su formación en Didáctica de la Matemática. Por sus negativas consecuencias, estas modificaciones fueron fuertemente criticadas por el profesor Orellana.

La «matematización» de la Maestría provocó que el curso de Historia de la Matemática (HM), que tenía carácter obligatorio, pasara a ser un curso electivo. Este cambio de orientación fue considerado erróneo por el profesor Orellana debido a que, según su punto de vista, los profesores que enseñan Matemática en la Educación Secundaria, quienes lo hacen en los primeros semestres universitarios y quienes pretenden investigar sobre la Enseñanza de la Matemática «deben conocer la historia de la Matemática ya que permite conectarse con lo que se pretende enseñar. [...] sobre todo cuando se enseña algo de una manera distinta a su génesis» (Mauricio Orellana, entrevista personal, septiembre 2I, 2019).

\subsection{Primer magister en Educación Matemática en Latinoamérica}

El primer egresado de la MEM-IPC fue el profesor José Clemente Ventura; su trabajo especial de grado, intitulado La Formación de profesores de Matemática, fue presentado en junio de 1977 ante un jurado integrado por los profesores Margarita de Sánchez, Saulo Rada y Heberto Urdaneta (tutor). 
En su trabajo de investigación el profesor Clemente abordó los cambios de orientación que debían tener los programas de formación de profesores de Matemática, tomando en cuenta las transformaciones en la educación que tuvieron lugar durante las décadas de los años 50, 60 y 70, apreciando que la tendencia principal indicaba el pasaje de una estructura humanística a una estructura tecnificada. Luego de una revisión minuciosa de las tendencias en la formación y actualización del profesorado de Matemática vigentes en la época, el profesor Clemente analizó las recomendaciones que se habían formulado sobre la formación de profesores en Matemática, tanto a nivel nacional como mundial.

El acto solemne de conferimiento del Título de Magíster en Educación Matemática (Imagen I) al profesor Clemente se llevó a cabo el 29 de octubre de 1977.

Imagen I. Título de Magíster en EM profesor José Clemente Ventura (1977), foto cortesía de la profesora Clemencia de Clemente (via Whatsapp, octubre 24, 2019).

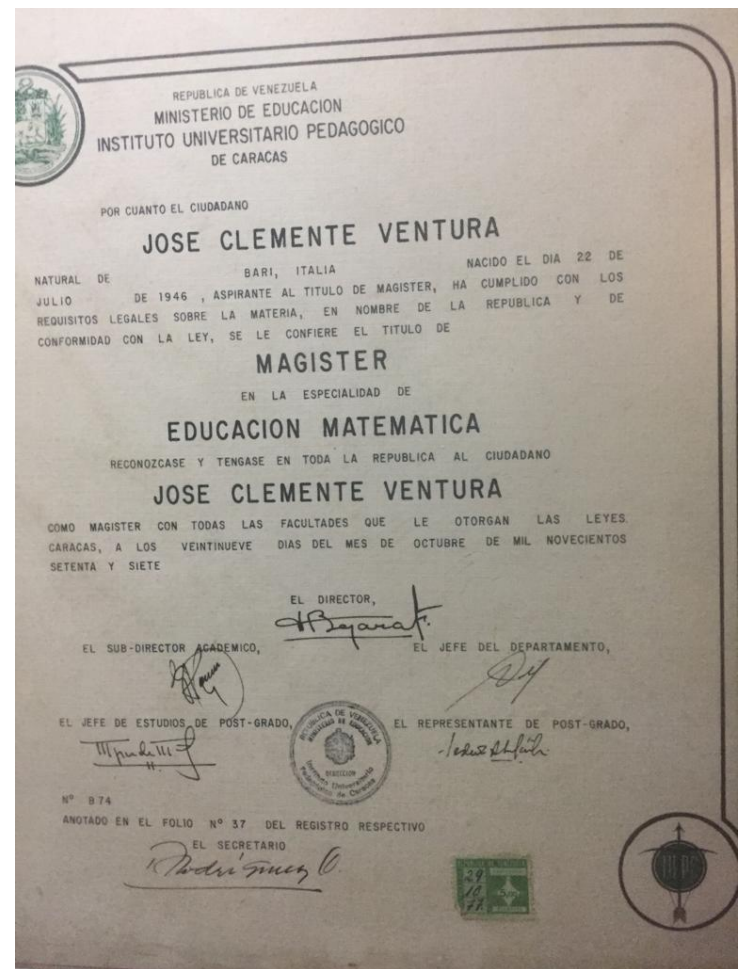

\subsection{Impulso de la Maestría en Enseñanza de la Matemática (1980-2015)}

Durante casi una década (1974-1982) el número de egresados de la MEM-IPC fue muy bajo, manteniéndose estancada hasta que, en 1987 , asumió la coordinación del programa el profesor Rafael Sánchez Lamoneda, formado como profesor 
de Matemática en el Instituto Pedagógico de Caracas, magíster en Matemática por la Universidad Simón Bolívar de Caracas, graduado en el año 1979, doctor en Matemática por la Universidad de Brandeis.

A partir de ese momento se produce un reimpulso en la Maestría. Había la necesidad de generar cambios en la concepción del programa de la MEM-IPC porque los institutos pedagógicos existentes en el momento habían alcanzado rango de universidad al ser integrados en 1983, para constituir la Universidad Pedagógica Experimental Libertador, UPEL. Esta circunstancia favoreció que en la reestructuración de la Maestría se incluyeran más cursos relativos a Educación Matemática.

\section{El Programa de Maestría en Enseñanza de la Matemática del IPC (1974)}

Entre los argumentos presentados para justificar la creación de este programa (Orellana, 1974) destacan los siguientes:

I. La importancia atribuida al estudio de la Matemática en relación con el papel que desempeña en el desarrollo de las habilidades de pensamiento de los ciudadanos y de sus capacidades para resolver problemas.

2. La constatación de «los graves problemas de aprendizaje y enseñanza que existen en todo el sistema educativo venezolano y, en especial, en el área de la Matemática».

3. Muchos de los profesores que enseñaban Matemática en diversos niveles del sistema educativo venezolano no eran profesionales de la docencia, sino que provenían de otras áreas o eran maestros normalistas que no tenían preparación específica en la disciplina.

Con la idea de contribuir a la superación de dichos problemas, Orellana (1974) y los profesores que conformaron su equipo de trabajo concibieron la MEM-IPC como un estudio a nivel de postgrado para formar profesionales:

a) «especializados en la enseñanza y aprendizaje de la Matemática»;

b) poseedores de «una preparación metodológica para la investigación, de modo que puedan diseñar y ejecutar estudios que aborden problemas identificados en cualquiera de las instancias o aspectos de la enseñanza y el aprendizaje de la Matemática»;

c) dotados de «herramientas teórico-metodológicas que les permitan diseñar, ensayar y evaluar experiencias de aprendizaje adecuadas a los niveles, modalidades o programas educativos en los cuales se desenvuelven como docentes», y

d) poseedores de una amplia formación en Matemática que les permita desarrollar «una visión más profunda de los problemas de su enseñanza».

El programa MEM-IPC hacía un llamado a profesionales diversos: profesores de Matemática, profesores de Matemática y Computación, licenciados en 
VANESA PACHECO MOROS Y FREDY ENRIQUE GONZÁLEZ

Educación mención Matemática, licenciados en Matemática y profesionales con otro título de Educación Superior que poseyeran experiencia o estuviesen dedicados a la enseñanza de la Matemática en diversos niveles del sistema educativo, teniendo como objetivo superar los problemas que habían sido identificados en la formación matemática de los ciudadanos.

Sin embargo, para ingresar a la MEM no era suficiente poseer un título asociado con Matemática, era necesario satisfacer otras condiciones, las cuales eran verificadas en dos instancias: la primera implicaba una evaluación de credenciales, la asistencia a una entrevista, la escritura en un máximo de dos cuartillas de las razones por las cuales desea ingresar al programa y presentación y aprobación de una prueba de conocimientos; la segunda instancia consistía en la aprobación de un Curso Propedéutico.

Para obtener el grado de Magíster, era necesario:

a) Cursar y aprobar 8 cursos obligatorios (Álgebra, Geometría y Álgebra Lineal, Análisis, Problemática de la Enseñanza de la Matemática, Metodología de la investigación en Enseñanza de la Matemática I, Metodología de la investigación en Enseñanza de la Matemática II, Tutoría I y Tutoría II; 26 Unidades Créditos), y al menos 2 cursos electivos seleccionados entre una oferta amplia de opciones (Tópicos de Álgebra, Tópicos de Geometría, Tópicos de Análisis, Probabilidad y estadística, Introducción a la computación, Tópicos de aplicaciones de la matemática, Juegos en la enseñanza de la matemática, Historia de la Matemática, Resolución de problemas en matemática, Evaluación en la enseñanza y aprendizaje de la matemática, Computación y enseñanza de la matemática, Tecnología educativa para la enseñanza de la matemática, Didáctica de la matemática, Estudio independiente; 12 Unidades Crédito);

b) Elaboración, presentación y aprobación de un Trabajo de Grado de Maestría;

c) Demostración de suficiencia en el dominio instrumental de un idioma distinto al castellano.

\section{I. La MEM-IPC, pionera de los estudios de postgrado en Educación Matemática de América Latina}

Los países latinoamericanos con los programas de postgrado en Educación Matemática más antiguos son Brasil, México y Venezuela. Se asumieron estos dos países para compararlos con Venezuela porque las datas de creación de sus respectivos programas son las que más se aproximan a la data fundacional de la MEM en el Instituto Pedagógico de Caracas (Venezuela).

La Maestría en Ciencias con especialidad en Matemática Educativa de la Universidad de Sonora, México, fue fundada a finales de los años setenta, como iniciativa de la Sección de Matemática Educativa del Departamento de Matemáticas 
del Centro de Investigación y de Estudios Avanzados del Instituto Politécnico Nacional (CINVESTAV-IPN), apoyada por la Secretaría de Educación Pública (SEP). En relación con esto, la Universidad de Sonora (20I5) señala que:

La iniciativa llegó a la Universidad de Sonora con el objeto de formar uno de los tantos Centros de Investigación y Experimentación Educativa en Matemáticas que se pretendían para el país y una de las acciones que cristalizaron fue la formación de un grupo de maestros en ciencias, con esa especialidad, cuyo propósito fue el de proveer a la Universidad de Sonora de un equipo de académicos que promoviera la creación de un programa propio (Universidad de Sonora, 2015: 2).

Se percibe que, aunque la problemática planteada es semejante a la de Venezuela, en relación con la preparación de los profesores que enseñan matemática, la intencionalidad de la creación de un programa es otra: satisfacer necesidades institucionales.

Ese programa tuvo como propósito formar Maestros en Ciencias con la intención estratégica de crear un espacio propio en el campo de la Matemática Educativa, lo cual fue alcanzado posteriormente, en enero de 1984, cuando fue aprobado el programa de Maestría en Matemática Educativa; sin embargo, no fue sino hasta la década de los noventa cuando el programa fue actualizado y puesto en funcionamiento, conforme lo suscribe la mencionada Universidad:

El 16 de enero de 1984, el H. Consejo Universitario aprobó un programa de postgrado propio, denominado Maestría en Matemática Educativa, propuesto por un grupo de profesores del Departamento de Matemáticas que ya había alcanzado su formación en este campo, pero no fue sino hasta el año de r99o que el Programa se actualizó y se puso en marcha. Como su objetivo más general, el Programa ha impulsado la formación de docentes e investigadores que, integrando conocimientos matemáticos con teorías y metodologías educativas, enfrenten de mejor manera los problemas que plantean los procesos de enseñanza y de aprendizaje de las matemáticas, habiéndose logrado hasta la fecha una significativa incidencia regional en esa dirección (Universidad de Sonora, 20I5: 3) (cursivas añadidas).

Como se aprecia, la creación de la Maestría en Matemática Educativa de la Universidad de Sonora (UdeS) fue aprobada en enero de 1984, casi diez años después de la aprobación de la MEM-IPC.

De acuerdo con lo señalado por Ávila (2016), la Maestría de la UdeS se inició en 1975 y en 1980 fue cuando «se propuso la formación de especialistas en educación matemática con orientación hacia la investigación. [...] preparó el terreno para la creación del campo de la educación matemática. Poco después se abrió el doctorado, (cuyas primeras tesis) se presentaron a finales de I980" (Ávila, 2016: 34) (paréntesis añadidos).

De acuerdo con Ávila (2016), la Educación Matemática en México tuvo sus orígenes a finales de la década de los setenta del s. xx, cuando el grupo del CINVESTAV propuso la creación de una Maestría en Ciencias, con especialidad en Matemática Educativa. Estos estudios estuvieron enfocados hacia la investigación sobre la enseñanza y el aprendizaje de las matemáticas. Con este programa de maestría se abonó el terreno para la creación del campo de la Matemática Educativa en México. 
Tomando en cuenta que fue en 1975 cuando se creó la Maestría de la UdeS, puede decirse que México es el país que más se acerca a Venezuela con respecto a la data de creación de un programa de maestría en Matemática Educativa.

En cuanto a Brasil, los orígenes del primer programa de postgrado específico en Educación Matemática fundado en ese país se remontan a la década de i97o. En esa época fue creada la Faculdade de Filosofia, Ciências e Letras (FFCL) de Rio Claro, y allí nacería como un movimiento pedagógico de enorme trascendencia el Serviço Ativador em Pedagogia e Orientação (SAPO), bajo la conducción del profesor Mario Tourasse Teixeira (1925-1993). Aunque la actividad del SAPO se circunscribió principalmente a la FFCL (Souto, 2009: 9), su impacto a la larga se sentiría en todo el espacio nacional brasileño; tanto así, que puede considerársele como el precursor de una historia que varios años después culminaría con la creación del Programa de Pós-Graduação em Educação Matemática de la UNESP/ Rio Claro (Garnica y Souza, 20I2: 212).

De acuerdo con Souto (2009: Io), junto con el GEEM -Grupo de Estudos do Ensino da Matemática-, con sede en la Universidade Mackenzie de São Paulo, en I96I; el GEEMPA -Grupo de Estudos sobre o Ensino da Matemática-, en Porto Alegre, en 1970; y el GEPEM -Grupo de Estudos e Pesquisas em Educação Matemática-, en Rio de Janeiro, entre otros, el SAPO fue una de las iniciativas cuyo accionar dio impulso al desarrollo de la Educación Matemática en Brasil. Muchas de las ideas de su creador, el profesor M. T. Teixeira, fueron asumidas por quienes, durante alguna fase de su trayectoria profesional, hicieron escala en Rio Claro. Esto sirvió de aliento al proceso de creación de los estudios de postgrado en Educación Matemática en el país, el cual se vio completado con la creación del Programa de Pós-Graduação em Educação Matemática de la UNESP, Campus de Rio Claro, el primero en su género acreditado en Brasil.

En las investigaciones llevadas a cabo tanto por Mauro (1999) como por Baccan (2002), ambas orientadas por el profesor Sergio Roberto Nobre, se rinde cuenta de las actividades del SAPO y de la influencia que este tuvo en el desarrollo de la Educación Matemática en Brasil y, muy especialmente, en la creación, en 1984, del Programa de Pós-Graduação em Educação Matemática da UNESP-Rio Claro.

En síntesis, el SAPO que se desarrolló en la UNESP-Río Claro desplegó una actividad extremadamente productiva e influyente desde el punto de vista de la Matemática profesional; además, creó un ambiente propicio de lo que luego serían los estudios de Postgrado en Educación Matemática, expresándose concretamente en la creación del programa de Maestría en Educación Matemática en 1984 (Garnica y Souza, 2012).

\subsection{Linea del Tiempo de los tres primeros programas de Maestría en Educación Matemática de América Latina}

Como fue evidenciado en las secciones anteriores, los tres primeros programas de postgrado en Educación Matemática de América Latina fueron creados en Brasil, México y Venezuela, correspondiéndole a este tercer país el privilegio 
de ser la sede de la primera Maestría en Educación Matemática surgida en nuestra región. En la Imagen II se muestra gráficamente la Línea del Tiempo de estos tres primeros programas.

\section{IMAgen II. Linea del Tiempo de los tres primeros programas de postgrado} en Educación Matemática creados en América Latina.

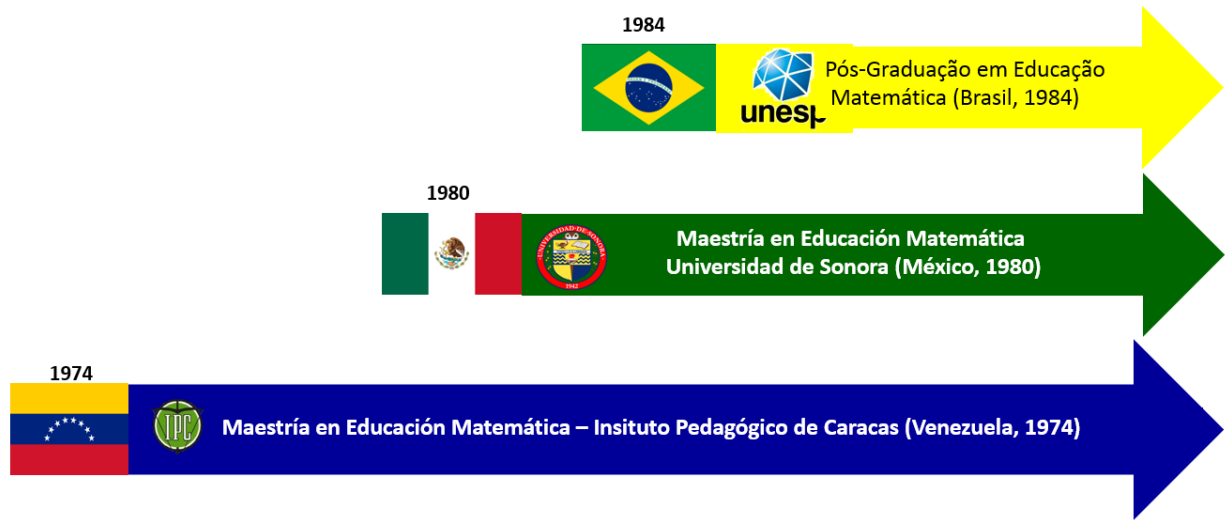

\section{Consideraciones finales}

Transcurridas casi cinco décadas de haberse iniciado los estudios de postgrado en Educación Matemática en América Latina, el panorama hoy es muy prometedor. Se cuenta con una comunidad de educadores matemáticos sólida; en casi todos los países de la región existen instancias que los agrupan, y conforman la Federación Iberoamericana de Sociedades de Educación Matemática (FISEM), la cual, junto con el Comité Interamericano de Educación Matemática (CIAEM), el Comité Latinoamericano de Matemática Educativa (CLAME) y la Red de Educación Matemática de América Central y El Caribe (REDUMATE), entre otras (Ruiz, 2013), impulsa la consolidación de la Educación Matemática como disciplina científica.

Además de la constitución de asociaciones nacionales, otros indicios de la consolidación disciplinaria de la Educación Matemática son: los congresos institucionales, locales, regionales, nacionales e internacionales, entre los que destacan la CIAEM, la RELME, el CIBEM y el ICME; las revistas especializadas en Educación Matemática como Cuadernos de Investigación y Formación en Educación Matemática (Costa Rica), HISTEMAT, BOLEMA, ZETETIKÉ (Brasil), RELIME (México); una multitud de líneas de investigación consolidadas, además de Grupos de Estudio muy activos como el GHEMAT (Brasil) y el NIEM (Venezuela). 
UNA HISTORIA DEL PRIMER PROGRAMA LATINOAMERICANO

DE POSTGRADO EN EDUCACIÓN MATEMÁTICA

VANESA PACHECO MOROS Y FREDY ENRIQUE GONZÁLEZ

Finalmente, vale decir que la Maestría en Educación Matemática de Venezuela se mantiene activa luego de las modificaciones propias de los cambios en las condiciones sociales y académicas del país, especialmente la unificación de todos los institutos pedagógicos para constituir la Universidad Pedagógica Experimental Libertador (UPEL).

\section{Bibliografía}

Agudelo, A.: «Prólogo», en Bethencourt, B. (ed.): Historia de los Departamentos del Instituto Pedagógico de Caracas, Caracas, Fondo Editorial Mariano Picón Salas del Instituto Pedagógico de Caracas, 20I6, pp. I5-I8. Disponible en: https://www.academia.edu/29402673/ Departamento_de_Ciencias_de_la_Tierra_pdf.

Ávila, A.: «La investigación en educación matemática en México: una mirada a 40 años de trabajo", Educación Matemática, 28 (3) (diciembre, 20I6), pp. 3I-59. [Documento en línea]. Disponible en: http://www.revista-educacion-matematica.org.mx/descargas/Vol28/3/2. pdf. Acceso: 25 de julio de 2020.

Baccan, N. R.: O movimento do S.A.P.O. - Serviço Ativador em Pedagogia e Orientação - e algumas de suas contribuições para a Educação Matemática, $224 \mathrm{ff}$. Dissertação (Mestrado em Educação Matemática), Rio Claro, UNESP,2002.

Bourdieu, P.: «El campo científico», Redes: Revista de Estudios Sociales de la Ciencia, I (2), (1994), pp. I29-I60. Disponible en RIDAA-UNQ Repositorio Institucional Digital de Acceso Abierto de la Universidad Nacional de Quilmes http://ridaa.unq.edu.ar/handle/20.500.11807/317.

Garnica, A. V. M. y Souza, L. A. de: Elementos de História da Educação Matemática, São Paulo, Cultura Acadêmica, 384 pp., 2012.

Mauro, S.: A história da Faculdade de Filosofia, Ciências e Letras de Rio Claro e suas contribuições para o movimento de educação matemática, 159 pp. Dissertação (Mestrado em Educação Matemática), Rio Claro, Instituto de Geociências e Ciências Exatas, Universidade Estadual Paulista, I999.

Orellana, M.: Desarrollo del plan «Maestría en Enseñanza de la Matemática», manuscrito no publicado, Instituto Pedagógico de Caracas, 1973.

Orellana, M.: Programa versión final "Maestría en Enseñanza de la Matemática», Instituto Pedagógico de Caracas, datos no publicados, 1974.

Orellana, M.: Dos décadas de Matemática en Venezuela, Caracas, Universidad Nacional Abierta, 1980.

Ruiz, A.: «El CIAEM y las organizaciones internacionales de Educación Matemática en América Latina», Cuadernos de Investigación y Formación en Educación Matemática, año 8, n. ${ }^{\circ}$ II (2013), pp. I5-25. Costa Rica.

Souto, R. M. A.: «O movimento do S.A.P.O. na década de 1970 e a educação matemática em Rio Claro - aspectos históricos», Zetetike,I5 (I) (2009), pp. 9-24. https://doi.org/I0.20396/ zet.visi27.86470I3

Universidad de Sonora: Plan de Estudios 20i5, Programa de Maestría en Ciencias con especialidad en Matemática Educativa, México, Universidad de Sonora División de Ciencias Exactas y Naturales Departamento de Matemáticas, 2015. [Documento en línea]. Disponible: http://pmme.mat.uson.mx/docs/Plan2ors.pdf. 
